\title{
Emergency situations in rheumatology with a focus on systemic autoimmune diseases
}

\author{
Jiri Vymetal, Martina Skacelova, Andrea Smrzova, Anna Klicova, Marketa Schubertova, Pavel Horak, Josef Zadrazil
}

Background and Aim. Rheumatic diseases are commonly considered chronic conditions. However, acute manifestations can be very severe and represent a diagnostic problem. Examples are systemic lupus erythematosus with acute flare, glomerulonephritis, CNS disorders and catastrophic antiphospholipid syndrome, scleroderma with interstitial lung disease, pulmonary hypertension and renal crisis and polyangiitis with alveolar haemorhage and acute respiratory failure. This aim of this paper is to overview emergency situations which can be encountered in the care of patients with autoimmune systemic diseases and vasculitides.

Methods. A Pubmed search for both original and review articles, recent textbooks and current guidelines related to rheumatic diseases with possible acute situations were included in this review article. Relevant image documentation was obtained at the site over the past several years of observation.

Conclusions. This paper provides an overview of facts and emergency situations which can be encountered in the care of patients with autoimmune systemic diseases and vasculitides. It is directed at clinicians working in intensive care. It provides a differential diagnostic overview and information which is rare and commonly underestimated.

Key words: SLE, scleroderma, polyangiitis, dermatomyositis, emergent

Received: July 2, 2015; Accepted with revision: January 22, 2016; Available online: February 10, 2016

http://dx.doi.org/10.5507/bp.2016.002

Intensive Care Unit of the Department of Internal Medicine III - Nephrology, Rheumatology and Endocrinology, University Hospital Olomouc and Faculty of Medicine and Dentistry, Palacky University Olomouc, Czech Republic

Corresponding author: Jiri Vymetal, e-mail:jiri.vymetal@fnol.cz

\section{INTRODUCTION}

Rheumatic diseases are in general chronic, slowly developing and progressing illnesses. Nevertheless, acute flares and corresponding symptoms are not infrequent, and can reflect an emergency and life-threatening event, requiring urgent intervention and intensive care. Patients with rheumatic disease may be referred to different medical departments (e.g. rheumatology, internal medicine, neurology, or cardiology) according to predominant symptom(s). The complexity of systemic disease signs and symptoms requires, in the case of life-threatening events/ complications, multidisciplinary cooperation, including rheumatologist's consultancy, and immediate patient's admission to the ICU, to ensure adequate comprehensive intensive care.

\section{Covered areas}

The list of rheumatic diseases and related health statuses could be an extensive one. In this article, however, we shall focus on diseases with major clinical impact, i.e. systemic connective tissue disorders and vessel inflammatory disorders (vasculitis). Apart from basic clinical definitions and a general description of the diseases, we focus on the disease specific, life-threatening manifestations. Table 1 provides an overview of the field.

\section{SYSTEMIC LUPUS ERYTHEMATOSUS (SLE)}

\section{Definition}

SLE is an autoimmune inflammatory disease, predominantly affecting fertile women. Hyperactivity of B-cells is characteristic of the disease, together with overproduction of organ nonspecific autoantibodies that may participate on immunocomplexes formation. Deposition of immunocomplexes leads to tissue inflammatory impairment. Given that SLE is a highly heterogenic disorder, its clinical picture is rather assorted. In general, SLE can be split into several, clinically and laboratory defined subtypes.

\section{Signs and symptoms}

Fever, fatigue and weight loss are frequent symptoms of an acute flare of SLE. The course of the disease is characterized by remissions and exacerbations. Production of organ nonspecific antibodies against nuclear, cytoplasmic as well as cell surface self-antigens is one of the typical characteristics of the disease. Most frequent clinical symptoms include skin, joints, cardiovascular and renal disorders, as well as impaired respiratory and nervous systems and hemopoesis. Active SLE may end-up in the afflicted organ failure. Severe forms of the disease are associated with marked mortality. 
Table 1. Acute disorders in systemic rheumatic diseases.

\begin{tabular}{|c|c|}
\hline Type of disease & Possible related acute disorder \\
\hline Rheumatoid arthritis & $\begin{array}{l}\text { atlantoaxial dislocation } \\
\text { scleromalacia perforans } \\
\text { vasculitis }\end{array}$ \\
\hline SLE (Systemic lupus erythematosus) & $\begin{array}{l}\text { seizures, psychosis, encephalopathy } \\
\text { pericarditis, myocarditis, endocarditis } \\
\text { pneumonitis, ARDS, } \\
\text { acute glomerulonephritis } \\
\text { hypertensive crisis } \\
\text { acute pancreatitis } \\
\text { polyserositis } \\
\text { infection/sepsis }\end{array}$ \\
\hline Antiphospholipid syndrome & $\begin{array}{l}\text { acute cerebrovascular event } \\
\text { acute myocardial infarction } \\
\text { retinal vascular thrombosis } \\
\text { pulmonary embolism and infarction } \\
\text { placental ischemia, spontaneous abortion } \\
\text { catastrophic antiphospholipid syndrome }\end{array}$ \\
\hline $\begin{array}{l}\text { Scleroderma and mixed connective tissue disease (MCTD, } \\
\text { Sharp's syndrome) }\end{array}$ & $\begin{array}{l}\text { renal crisis } \\
\text { right-sided heart failure } \\
\text { digital ischemia }\end{array}$ \\
\hline Dermatomyositis & $\begin{array}{l}\text { acute lung disease, respiratory failure } \\
\text { bowel perforation }\end{array}$ \\
\hline Vasculitis & $\begin{array}{l}\text { pulmonary-renal syndrome } \\
\text { rapidly progressive glomerulonephritis acute renal failure } \\
\text { acute lung disease, respiratory failure } \\
\text { pancreatitis } \\
\text { encephalopathy } \\
\text { arterial and venous thrombotic complications } \\
\text { necrosis }\end{array}$ \\
\hline Parainfectious manifestations & $\begin{array}{l}\text { reactive arthritis } \\
\text { septic arthritis } \\
\text { septic spondylodiscitis } \\
\text { pyogenic myositis }\end{array}$ \\
\hline
\end{tabular}

MCTD - mixed connective tissue disorder, ARDS - acute respiratory distress syndrome

\section{Life-threatening disorders in SLE}

\section{Heart and cardiovascular system impairment}

Cardiac impairment is quite frequent in SLE. In general, there are four major forms:

Valve impairment (Valve disease)

Mitral regurgitation is the most frequent event, usually hemodynamically insignificant. Valvular vegetation of variable size, from small nodules to large verrucous vegetation (Libman-Sacks endocarditis), are the most frequent cause of the valve dysfunction and/or insufficiency (mitral valve insufficiency is more frequent than aortal valve insufficiency) $\left(\right.$ ref. $\left.^{1}\right)$.

\section{Pericardial disorders}

Pericarditis, together with pleuritis and diffuse peritonitis are classified within the group of serositis. Pericarditis, which is often asymptomatic ${ }^{2}$, frequently associates with other serositis in active SLE. Sharp and stabbing pain localized behind the lower part of the breastbone (sternum) is a typical symptom, frequently coupled with pleural friction rub. Large volume pericarditis, with high risk of cardiac (pericardial) tamponade is rare.

\section{Myocardial dysfunction}

Signs of heart failure, tachycardia or arrhythmia may be reflections of a myocardial dysfunction, accompanied by cardiomegaly. Diastolic impairment is the most frequent finding on echocardiogram, however, dilatation and diffuse hypokinesia with depression of the left ventricle systolic function may be found too. Acute myocarditis often goes together with pericarditis ${ }^{3}$.

\section{Ischemic heart disease}

Cardiovascular mortality related to SLE reflects one of the highest mortality figures, out of the total cardiovascular mortality. The myocardial infarction relative risk 
in SLE corresponds to 2.27; the relative risk for CVA (stroke) equals to 2.05 and the relative risk for atherosclerosis rises to 7.1. Atherosclerosis genesis is related to a higher presence of traditional risk factors (obesity, smoking, metabolic syndrome), however, other factors specific for active SLE are involved in its subsequent development (disease activity, antiphospholipid antibodies, immunocomplexes, drug related adverse effects) (ref. ${ }^{4}$ ).

\section{Acute lung disease}

Lupus pneumonitis is a rare manifestation of active SLE disease. Its symptoms include fever, breathlessness, productive cough (with small quantity of sputum), tachypnea, hemoptysis, pleuritic pain and hypoxemia. Physical examination will display bilateral basal crepitus, and central cyanosis in more severe cases. Bilateral patchy alveolar infiltrates may be found on chest X-ray. Therefore, an infection as a potential option must be diagnostically excluded 5 .

Pulmonary hemorrhage is a rare ${ }^{6}$, but serious and frequently fatal event. It shows clinical course similar to lupus pneumonitis, with rapid progression and deterioration of patient health status, which causes significant patient anxiety. Tachypnea, hypoxemia and tachycardia are regularly found, and ARDS can easily evolve (Fig. 1). Intraalveolar or external hemorrhage can be present, with frequent and rapid hemoglobin level reduction. Histopathology provides evidence of intraalveolar bleeding, with intact erythrocytes and macrophages packed with hemosiderin. Vasculitis may not be exhibited; nonetheless, microangiitis has been described from time to time, which corresponds to inflammatory necrosis of alveolar capillaries and small muscular arterioles.

Acute reversible hypoxemia: Its pathogenesis remains unclear. Oxygenation capacity of the lung may be reduced due to neutrophil aggregation within the pulmonary vessels. Inside neutrophils we can see residues of the complement decay ${ }^{7,8}$.

\section{Central Nervous System Impairment - Neuropsychiatric and neuropsychological Symptoms}

The prevalence of neuropsychiatric symptoms in SLE, as reported in clinical trials, is rather heterogeneous, ranging from $10 \%$ in early stages up to $80 \%$ during the later course of the disease ${ }^{9}$. This heterogeneity reflects different criteria for evaluation of CNS impairment in SLE. The American College of Rheumatology (ACR) has defined the standards for diagnosis of 19 neuropsychiatric symptoms accompanying SLE. Detailed description of the standards is available on: www.rheumatology.org/publications/ar/1999/aprilappendix.asp?aud=mem.

\section{Cerebral infarction}

The risk of cerebral infarction and sudden death is significantly increased for patients with SLE. The cerebral infarction may be presented either as a classical stroke or as a transitory ischemic attack. The recurrence risk is high. There is a strong association between these events and antiphospholipid antibodies ${ }^{10}$. Patients with antiphospholipid syndrome usually suffer from repeating transitory ischemic events. These can lead to a significant cognitive disorder.

\section{Seizures}

Generalized or partial seizures may be the primary symptom of the disease. Their ethiopathogenesis is diverse, could be the inflammatory damage of the CNS or the presence of an "old" scar. The presence of the antiphospholipid antibodies may increase the risk of seizures, as well as hypertension, infection, tumors, injuries, ischemic cerebral events, vasculopathies or drug toxicity (e.g. high doses of antimalarial) can $\mathrm{do}^{11}$. Seizures with no clear local etiology (negative findings on angiogram, CT scan or MRI) probably result from existing vasculopathy.

\section{Acute confusional episodes}

In SLE these are multifactorial, partly due to the disease activity, partly due to metabolic disorders and/or therapy. The status reflects the complexity of the disorder, with reduced ability to maintain attention and/or concentration. Behavioral and mood disorders, psychomotor restlessness and different levels of consciousness disorders may accompany episodes. These delirious conditions, developing within few hours or days, may end up in coma ${ }^{12}$.

\section{Renal impairment}

Renal impairment per se and/or in combination with medication-induced nephrotoxicity may significantly increase both morbidity and mortality in patients with SLE. Appropriate diagnosis is based on detailed clinical and laboratory examinations, with supplementary histological examination of renal biopsy, if needed ${ }^{13}$.

Glomerulonephritis is the fundamental pathogenic factor of renal impairment in SLE. According to WHO classification (revision 4), there are 6 basic histological classes of glomerulonephritis, which currently have been amended by activity and chronicity indexes. Lupus nephritis is often diagnosed in younger patients with symptomatic SLE. The degree of renal insufficiency and nephritis related proteinuria can vary individually ${ }^{14}$.

Vascular pathology Capillary microthrombi or thrombosis of renal vessels are the major cause of the acute renal failure in the context of SLE complication and antiphospholipid syndrome ${ }^{15}$.

Acute interstitial nephritis is another potential manifestation of the disease. It is associated with immunocomplex deposits distributed along the tubular basal membrane. Both proximal and distal tubular syndromes are present in many SLE patients, and frequently linked to manifestations of secondary Sjögren's syndrome and positivity of anti-Ro (SSA) and/or anti-La (SSB) antibodies. This type of nephritis does not correlate with the existence and activity of glomerulonephritis ${ }^{16}$.

\section{Pregnancy and Lupus Erythematosus}

High disease activity before conception and preexisting renal impairment are major risk factors for the disease flare in the course of pregnancy or after its termination. The risk of flare has been partially reduced by comprehen- 
sive medical care and systematic monitoring of the SLE patients. On the other hand, the first manifestation of lupus during pregnancy or immediately after delivery may develop as a serious, even catastrophic case. The disease should be considered always in case of any relevant clinical symptomatology appears in the course of pregnancy ("butterfly" rash or other skin symptoms, alopecia, arthritis, proteinuria with active sediment, psychosis, chorea, pleurocarditis, vasculitis, etc.). Women with SLE have increased risk of preeclampsy and hepatopathy ${ }^{17,18}$.

\section{Diagnosis}

The disease diagnosis is based on the appropriate interpretation of history, clinical, laboratory and paraclinical findings. Determination of positivity of antinuclear autoantibodies (ANA), anti-dsDNA antibodies, ENA antibodies and antiphospholipid antibodies or reduced levels of complement play a crucial role in the disease diagnosis.

It is important, within the context of the SLE related life-threatening events, to rule out any other systemic connective tissue disorder and/or vasculitis, and particularly any potential infectious complication in differential diagnosis. Infections related to SLE often have an insidious course, which can be further altered by prescribed immunosuppressive therapy.

\section{Therapy}

Treatment of SLE is focused on management of the disease activity, maintenance of remission, prevention of severe organ impairment, and prevention or management of secondary complications. The treatment strategy is highly individual. Patients in advanced stage of the disease, with multiorgan failure should be managed first with the aim of saving their lives. In the stable disease, it is important to evaluate the disease activity, extent of organ impairment, quality of life, and potential toxicity of intended or already prescribed medication. It is important to mention, that many drugs commonly used in SLE are "off label". This concerns not only many of immunosuppressive drugs but also for example rituximab.

Table 2 summarizes simplified recommendations for the therapy of SLE, according to a type and severity of the disease ${ }^{19-21}$.

\section{Prognosis}

Prognosis of patients with the systemic lupus is changing hand to hand with advances in therapy options. The five-year survival was about $50 \%$, in the time before glucocorticoids had been introduced, and then went up to $75 \%$. Further, with the prescription of immunosuppressive therapy, $85-90 \%$ of treated patients do survive for at least 5 years. On the other side, we must be aware of the severe late adverse effects of glucocorticoid and/or immunosuppressive therapy, mainly the increased risk of osteoporosis, accelerated atherosclerosis, malignancies and infections ${ }^{22}$. In considering SLE therapy, efficacy and safety, or in other words, benefits and risks should always be well- balanced, for the individual patient with SLE.

Table 2. SLE therapy options, according to stage and severity ${ }^{19-21}$.

\begin{tabular}{|c|c|c|c|}
\hline Stage and severity & Induction therapy & Maintenance therapy & $\begin{array}{l}\text { Second line therapy (previous } \\
\text { therapy failure or intolerance) }\end{array}$ \\
\hline $\begin{array}{l}\text { Dermo-articular } \\
\text { form } \\
\text { No other organ } \\
\text { involved }\end{array}$ & $\begin{array}{l}\text { Hydroxychloroquine } 200-400 \mathrm{mg} \text { p.o. } \\
\text { Low dose prednisone } \\
(\leq 10 \mathrm{mg} / \text { day or } 0.125 \mathrm{mg} / \mathrm{kg} \text { EOD) }\end{array}$ & $\begin{array}{l}\text { Hydroxychloroquine } \\
200-400 \text { mg p.o. }\end{array}$ & $\begin{array}{l}\text { MTX }(7.5-25 \mathrm{mg} \text { week }) \\
\text { AZA }(1-3 \mathrm{mg} / \mathrm{kg} / \text { day }) \\
\text { Cyclosporin A }(2.5-5 \mathrm{mg} / \mathrm{kg} / \text { day }) \\
\text { Belimumab }(10 \mathrm{mg} / \mathrm{kg} / \mathrm{monthly})^{\#}\end{array}$ \\
\hline $\begin{array}{l}\text { Mild organ } \\
\text { impairment }\end{array}$ & $\begin{array}{l}\text { High dose prednisone } \\
(0.5-1.0 \mathrm{mg} / \mathrm{kg} / \text { day }) \text { - with stepping } \\
\text { down } \pm \mathrm{AZA}(1-3 \mathrm{mg} / \mathrm{kg} / \text { day }) \text {; } \\
\text { for } 3-6 \mathrm{months} \\
\text { Hydroxychloroquine } 200-400 \mathrm{mg} \text { p.o. }\end{array}$ & $\begin{array}{l}\text { Low dose prednisone } \\
(\leq 10 \mathrm{mg} / \text { day or } 0.125 \mathrm{mg} / \mathrm{kg} \\
\text { EOD) } \pm \text { AZA }(1-2 \mathrm{mg} / \mathrm{kg} / \text { day }) \\
\text { Hydroxychloroquine } \\
200-400 \mathrm{mg} \text { p.o. }\end{array}$ & $\begin{array}{l}\text { MTX (7.5-25 mg /week) } \\
\text { Cyclosporin A }(2.5-5 \mathrm{mg} / \mathrm{kg} / \text { day }) \\
\text { Belimumab (10 mg/kg/monthly })^{\#}\end{array}$ \\
\hline $\begin{array}{l}\text { Moderate organ } \\
\text { impairment }\end{array}$ & $\begin{array}{l}\text { High dose prednisone } \\
(0.5-1.0 \mathrm{mg} / \mathrm{kg} / \text { day) }- \text { with stepping } \\
\text { down }+\mathrm{MMF}(2 \mathrm{~g} / \text { day }) \text { or AZA } \\
(2-3 \mathrm{mg} / \mathrm{kg} / \text { day }) \text { for } 6-12 \mathrm{months} \text {, or } \\
6 \text { pulses of CFA (once a month) } \\
\text { Hydroxychloroquine } 200-400 \mathrm{mg} \text { p.o. }\end{array}$ & $\begin{array}{l}\text { Glucocorticoids + AZA } \\
(1-2 \mathrm{mg} / \mathrm{kg} / \text { day }) \\
\text { or MMF (1-1.5 g/day) } \\
\text { Hydroxychlorquine } \\
\text { 200-400 mg p.o. }\end{array}$ & $\begin{array}{l}\text { MTX (7.5-25 mg /week) } \\
\text { Cyclosporin A }(2.5-5 \mathrm{mg} / \mathrm{kg} / \text { day }) \\
\text { Belimumab }(10 \mathrm{mg} / \mathrm{kg} / \mathrm{monthly})^{\#}\end{array}$ \\
\hline $\begin{array}{l}\text { Severe organ } \\
\text { impairment }\end{array}$ & $\begin{array}{l}\text { Pulses of methylprednisolone }+ \\
\text { CFA (Once a month) } \\
+ \text { Prednisone } 0.5 \mathrm{mg} / \mathrm{kg} / \text { day p.o. } \\
\text { with stepping down, for } 6-12 \text { months } \\
\text { Hydroxychloroquine } 200-400 \mathrm{mg} \text { p.o. }\end{array}$ & $\begin{array}{l}\text { Glucocorticoids + AZA } \\
\text { (1-2 mg/kg/day) or MMF } \\
\text { (1-2 g/day) Hydroxychlorquine } \\
\text { 200-400 mg p.o. }\end{array}$ & $\begin{array}{l}\text { MMF 2-3 g/day and/or Rituximab } \\
\text { MTX ( } 7.5-25 \mathrm{mg} / \text { week }) \\
\text { AZA (1-3 mg/kg/day) } \\
\text { Cyclosporin A }(2.5-5 \mathrm{mg} / \mathrm{kg} / \text { day }) \\
\text { Belimumab }(10 \mathrm{mg} / \mathrm{kg} / \mathrm{monthly})^{\#} \\
\text { i.v. immunoglobulins ( } 400 \mathrm{mg} / \mathrm{kg} \\
\text { for } 4-5 \text { days) } \\
\text { Plasmapheresis }\end{array}$ \\
\hline
\end{tabular}




\section{ANTIPHOSPHOLIPID SYNDROME}

\section{Definition}

Antiphospholipid syndrome (APS) is represented by symptoms related to the presence of antiphospholipid antibodies (lupus anti-coagulant, anti-cardiolipine anti-bodies, anti-beta 2 glycoprotein anti-bodies). Antiphospholipid syndrome can exist per se, or it may accompany other systemic connective tissue disorders, especially SLE, as so-called secondary APS (ref. ${ }^{23}$ ).

\section{Signs and symptoms}

The coagulation disorders, associated with laboratory pathology (prolonged aPTT, with correction by plasma of a healthy donor; false positive Wassermann reaction), together with arterial and/or venous thrombosis and organ impairment are predominant symptoms of APS. Thrombocytopenia and other associated symptoms are frequently present. Stillbirth and spontaneous abortions may be pregnancy related APS symptoms.

\section{Life-threatening disorders}

Life-threatening disorders related to APS are mainly vascular thrombosis, pulmonary embolism, arterial occlusions, cerebrovascular event, and myocardial infarction or microangiopathic hemolysis. Preeclampsia, eclampsia and HELLP syndrome are potentially fatal APS related disorders connected with pregnancy. These are associated with a high risk of stillbirth or spontaneous abortion ${ }^{24}$. The catastrophic antiphospholipid syndrome is of special interest. It represents a rare manifestation of the disease, with a vast thrombotic disorder and multiorgan failure. It may be fatal, in association with the development of disseminated intravascular coagulation, with increased levels of fibrin degradation products, D-dimers and fibrinogen consumption $^{25}$. Clinical criteria of catastrophic antiphospholipid syndrome include:

- History of APS or presence of antiphospholipid antibodies

- Three or more episodes of organ thrombosis, within the last week

- Biopsy confirmation of microthrombi

- Exclusion of other reasons for organ thrombosis and microthrombi

\section{Therapy}

Therapy of primary and secondary APS is almost the same. In secondary APS, immunosuppression may be necessary to reduce the activity of the underlying basic pathology. Heparin (LMWH or unfractionated), warfarin and acetylsalicylic acid (ASA) are the most frequently used medication. Hydroxychlorquinoline may be beneficial for patients with SLE-APS. Treatment of APS related microangiopathy with hemolysis is similar to the treatment for thrombotic thrombocytopenic purpura/ hemolytic-uremic syndrome (TTP/HUS). Apart from symptomatic treatment, it includes repeated plasmapheresis in addition. The catastrophic APS therapy is based on elimination of potential stir-up infectious factors and combined medication with anticoagulants (heparin, LMWH) and high dose methylprednisolone, together with repeated plasmapheresis, in case of microangiopathy. Daily intravenous immunoglobulins, in a dose of $400 \mathrm{mg}$ per kilogram of body weight, may serve as add-on therapy. How many plasmapheresis are needed depends on clinical response. According to some reports, anti-cardiolipin anti-bodies reduction of $95 \%$ can be achieved after the fifth plasmapheresis. Use of rituximab may be beneficial too ${ }^{26}$.

\section{Prognosis}

If not recognized early enough, APS, especially its catastrophic form, may be fatal, with a high rate of mortality.

\section{SYSTEMIC SCLERODERMA (SSc)}

\section{Definition}

Systemic sclerosis or systemic scleroderma is a chronic connective tissue disease. CREST syndrome, also known as the limited cutaneous form of systemic sclerosis (1c$\mathrm{SSc}$ ), is a multisystem connective tissue disorder, which is limited mainly to the skin on the face, hands and feet. The acronym "CREST" refers to the five main features: Calcinosis, Raynaud's phenomenon, esophageal dysmotility, sclerodactyly and telangiectasia. Diffuse cutaneous scleroderma covers most of the skin, and is at risk of progressing to the visceral organs, including the kidneys, heart, lungs and gastrointestinal tract. The disease is characterized by fibrosing sclerosis of peripheral and visceral vessels, over production of collagen in connective tissues, changes in macro vascularity and by humoral and cellular immunity disorders.

\section{Signs and Symptoms}

Raynaud's phenomenon (RF) together with trophic changes and hardening of the skin are predominant symptoms of the disease (Fig. 2). Impairment of gastrointestinal tract, lung, heart and kidney may be present too, depending on the stage of the disease ${ }^{27}$.

\section{Life threatening manifestation of SSc}

\section{Renal crisis}

Renal impairment is a frequent symptom in SSc, mostly as mild renal insufficiency with a good prognosis ${ }^{28}$. On the other hand, severe renal crisis is an acute, serious and life-threatening event, with an incidence of $8-10 \%$ among patients with limited SSc and $10-20 \%$ in patients with diffuse form of the disease ${ }^{29}$. Usually, it develops within the first five years of onset of the disease. Renal crisis reflects thrombotic microangiopathy of kidney, and is similar to TTP/HUS or APS. The histology displays proliferation and thickening of arcuate and interlobular arteriole intima, resulting in narrowing or full obliteration of vessels. There appears the typical picture of concentric (onion-like) hypertrophy ${ }^{30}$. The prognosis of this event is poor. Before the introduction of ACE inhibitors (ACEI), almost all patients with severe renal insufficiency died within one year. Basic clinical symptoms of the renal crisis are: acute renal failure, without any warning signs, sudden 
onset of moderate or serious hypertension, which may be accompanied by signs of emergent hypertonic crisis (encephalopathy, left-sided heart failure, CVE). Risk factors for renal crisis involve rapid progressing diffuse scleroderma, high dose glucocorticoid and cyclosporine therapies, presence of anti-RNA-polymerase antibodies. Signs of proteinuria and/or hematuria, as evaluated in urine sediment, are mostly faint. Newly developed proteinuria or hematuria, progression of oliguria or anuria, and pulmonary edema may be complementary findings, together with characteristic histological findings in renal biopsy ${ }^{31}$.

\section{Diagnosis}

Basic clinical findings in renal crisis are:

- Acute renal failure, without any preceding signs of significant renal disorder

- Sudden onset of moderate or severe hypertension, often accompanied by emergent hypertonic crisis, which may be as follows:

○ Hypertonic encephalopathy (headache, confusion, visual disorders)

- Hypertonic retinopathy (hemorrhages, exudates)

- Acute cerebrovascular event (CVE)

- Discrete changes in urine sediment (mild proteinuria and/or hematuria)

\section{Therapy}

Effective and rapid (within $72 \mathrm{~h}$ ) control of blood pressure is the basic therapeutic measure. It provides stabilization of renal functions in almost $70 \%$ of patients and increase in one-year survival up to $80 \%$. ACE inhibitors, which are contraindicated in a majority of other forms of acute renal failure, seem to be appropriate treatment of renal crisis in SSc. Captopril was the most frequently drug used in clinical trials, however, enalapril, ramipril and quinapril may provide similar protective effects. ACEI therapy may provide significant improvement of renal function to allow interruption in regular dialysis treatment and decrease the need of permanent dialysis ${ }^{32}$.

The prognosis still remains unfavorable, mainly due to late diagnosis, and the rate of mortality is high.

\section{Interstitial lung disease (ILD)}

The most frequent interstitial changes are found in sub pleural areas of dorsal parts of both lower pulmonary lobes. In patients with moderate or severe restrictive disorder, interstitial changes propagate into upper parts of the lung field. Reduction in respiratory function, especially in forced vital capacity (FVC) can be detected early; reduction of FVC by $32 \%$ annually was detected in the first 2 years $^{33}$. ILD is associated with the high rate of mortality, which becomes conspicuous especially after five years of disease onset. Prognosis of patients with severe pulmonary impairment (FVC $<55 \%$ and DLCO $<40 \%$ of predicted normal values) is unfavorable; up to $42 \%$ die within 10 years of disease onset ${ }^{34}$.

\section{Diagnosis}

Diagnosis is based on the chest X-ray, spirometry and high-resolution computed tomography (HRCT) findings evaluation, together with bronchoalveolar lavage or lung biopsy analyses.

Therapy: Lower doses of glucocorticoids and cyclophosphamide may be used in active alveolitis therapy ${ }^{35}$.

\section{Prognosis}

The slowly progressing disease, which represents the majority of cases, has better prognosis than idiopathic interstitial pulmonary processes.

\section{Pulmonary arterial hypertension (PAH)}

It is the primary disorder of pulmonary arterioles. It accompanies systemic connective tissue diseases, mostly $\mathrm{SSc}$, where it may appear together with ILD. With respect to severity, the disease may be classified as mild, moderate or severe. From the hemodynamic point of view, PAH is defined as precapillary pulmonary hypertension, with mean pulmonary artery pressure (MPAP) values $>25 \mathrm{mmHg}$ in rest. Gradually progressive exercise breathlessness and fatigue are the most frequent symptoms of PAH. Anginal pains reflect ischemia of the right heart ventricle, while syncope and presyncope are signs of low cardiac output. One interesting symptom, caused by dilated pulmonary artery stem related recurrent nerve palsy, is hoarseness. Advanced PAH is presented by the right heart failure, which may lead to the terminal right ventricular failure.

\section{Diagnosis}

Echocardiography is the key noninvasive diagnostic tool in the case of PAH suspicion. Currently, it is used as a routine screening procedure. By mean of echocardiography, we can evaluate size and function of the right ventricle and estimate the pressure in the pulmonary artery. Measurement of the tricuspid valve regurgitation gradient by Doppler echocardiography, and estimation of the right atrial pressure from the vena cava inferior size are fundamental for the pulmonary hypertension evaluation. A right heart catheterization should be indicated in symptomatic patients with suspected even mild pulmonary hypertension and it is crucial for PAH diagnosis confirmation. DETECT algorithm may be helpful in selection and indication of patients for this invasive procedure $^{36}$.

\section{Therapy}

Warfarin, as an anticoagulant therapy, is used, to prevent potential pulmonary embolism. Endothelin-1 receptor antagonists (e.g. bosentan, ambrisentan, macicentan), phosphodiesterase inhibitors (e.g. sildenafil, tadalafil) or intravenous prostanoids (epoprostenol) represent current specific treatment of PAH. Early initiation of therapy is advocated $^{37,38}$.

\section{DERMATOMYOSITIS/POLYMYOSITIS (DM/PM)}

It is a chronic autoimmune inflammatory disease affecting striated skeletal muscles (polymyositis) or muscles and skin, with elevation of respective muscle enzymes 
levels in serum. The disease may also afflict esophagus and lung, and rarely myocardium.

Predominant symptoms are proximal muscle weakness and typical skin finding in dermatomyositis heliotrope rash and Gottron's papules.

\section{Life-threatening events in DM/PM}

Pulmonary manifestations of the disease are major life threatening events in DM/PM (ref. ${ }^{39}$ ). They often appear in patients with positivity for anti-synthetase antibodies (e.g. anti-Jo). Breathlessness or respiratory insufficiency may appear due to the interstitial fibrosis (Fig. 1) or as a result of respiratory restriction caused by weakness of respiratory muscles. Patients may be endangered by an increased risk of aspiration and related aspiration pneumonia, which is listed as one of the leading causes of death in patients with restricted mobility and swallowing disorders ${ }^{40}$. Diffuse fibrosing alveolitis may switch to pulmonary fibrosis.

\section{Diagnosis}

Respiratory function test, radiography, HRCT and bronchoalveolar lavage are used as standard diagnostic tools together with the disease focused tests, like the examination of serum muscle enzyme levels, EMG, muscle biopsy and immunology.

\section{Therapy}

Therapy is based on high dose glucocorticoids, often in combination with immunosuppressant (azathioprine, methotrexate). High dose polyclonal immunoglobulins may be used as well, if indicated.

\section{Prognosis}

Pulmonary manifestation is one of the major negative prognostic factors in patients with PM/DM. For patients with DM, prognosis is worse with than without the disease related pulmonary involvement ${ }^{41}$.

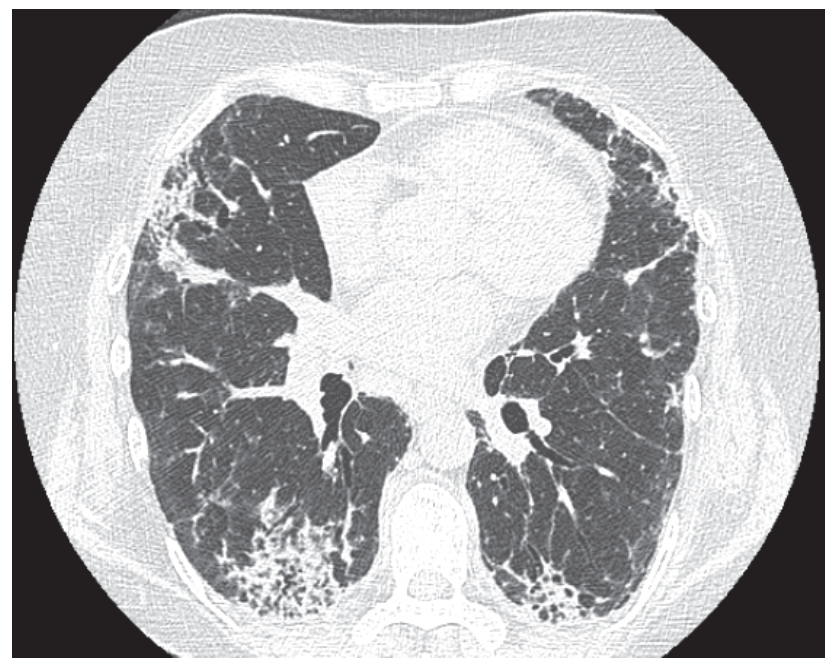

Fig. 1. Dermatomyositis: CT scan of peribronchial fibrosis (white "glass" opacities).

Department of Internal Medicine III - Nephrology, Rheumatology and Endocrinology. Archive of Department of Radiology.

\section{VASCULITIDES}

\section{Definition}

Vasculitides are a heterogeneous group of disorders, which are characterized by inflammation and necrosis of the vessel wall. The disease is often systemic, with multiorgan involvement. Primary vasculitis inflicts vessels of any size. Secondary vasculitis accompanies some rheumatic diseases, e.g. rheumatoid arthritis, SLE, or as a case nonrheumatic disorders (sarkoidosis, malignancies, serious bacterial infections).

Signs and Symptoms: Pulmonary and renal afflictions are the most serious manifestations of vasculitis.

\section{Diagnosis}

Appropriate interpretation of multiple data from clinical, laboratory and imaging examinations is crucial for the disease diagnosis set-up. This can be reached through the close multidisciplinary cooperation of rheumatologist, pneumologist, nephrologist and clinical pathologist. Evaluation of antibodies against neutrophil cytoplasm (ANCA) is a valuable tool in so-called "ANCA-associated" vasculitis. Positivity of ANCA antibodies is typical for syndromes like granulomatosis with polyangiitis (with anti-proteinase-3 specific antibodies, cANCA) and other ANCA related vasculitis (with anti-myeloperoxidase specific antibodies, p-ANCA) $\left(\right.$ ref. $\left.^{42}\right)$.

\section{Pulmonary impairment}

Serious pulmonary impairment appears mainly in ANCA associated vasculitis and pulmonary-renal (Goodpasteur's) syndrome ${ }^{43}$.

Granulomatosis with polyangiitis (formerly Wegener's granulomatosis) is an ANCA positive vasculitis with primary involvement of small vessels and frequent respiratory tract impairment. Chronic rhinitis and sinusitis, associated with granular inflammation can be found in the upper respiratory tract. Breakdown of bone structure with the collapse of nasal tissue and the saddle nose formation may be the chronic sinusitis complication. Ulceration of the nasal mucosa or perforation of the nasal septum is frequent. Pulmonary impairment is reflected as fever, breathlessness, cough, hemoptysis, pleurodynia, and seldom by tracheal obstruction. Stenosis of the large airways may be the consequence of the repair processes, and can threaten the patient's life. Stridor is a typical sign of severe stenosis. Pulmonary infiltrates, sometimes extensive, are quintessential signs of the disease, which may be associated with the tissue decomposition process, pulmonary hemorrhage and respiratory failure that need artificial lung ventilation. Correlation between the disease exacerbation and infection of the lower respiratory tract has been well established ${ }^{44}$. Development of pulmonary fibrosis is a chronic sequel of the disease.

Eosinophilic granulomatosis with polyangiitis (ChurgStrauss syndrome) is necrotizing ANCA-related vasculitis, associated with asthma, eosinophilia and the granulo- 


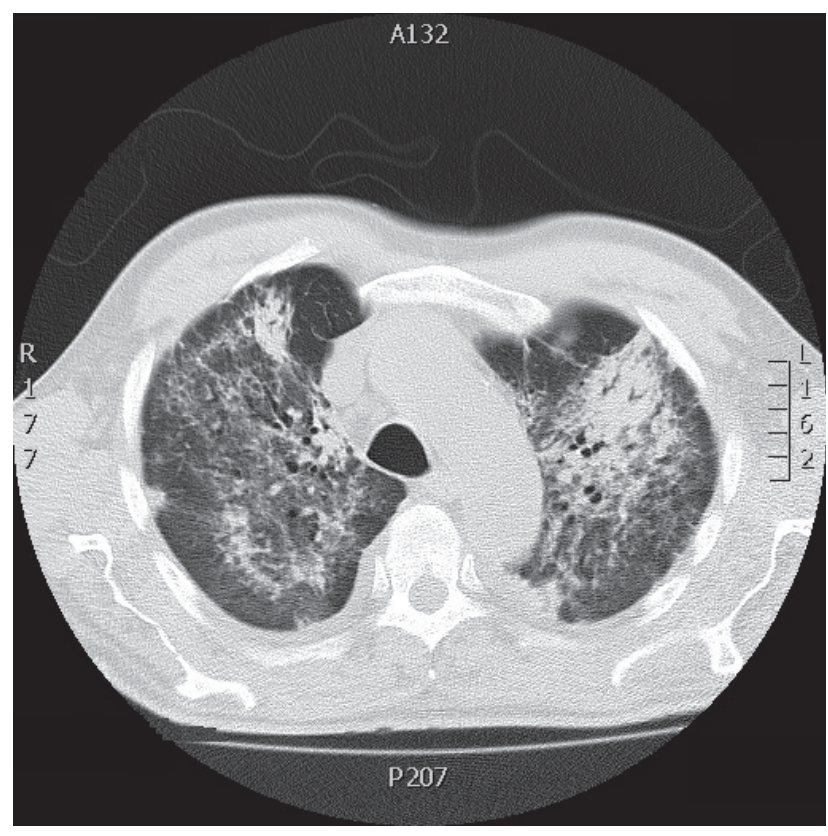

Fig. 2. CT scan of 75-year.old patient with ANCA positive microscopic polyangiitis shows extensive bilateral pulmonary inflammatory infiltrates, resulting in respiratory failure.

Department of Internal Medicine III - Nephrology, Rheumatology and Endocrinology. Archive of Department of Radiology.

matous respiratory tract infection. The chest X-ray may detect fugitive pulmonary infiltrates. The histology examination shows predominant extravascular granulomas, rich in eosinophils, and signs of necrotizing vasculitis ${ }^{45,46}$.

Microscopic polyangiitis is the necrotizing ANCA positive vasculitis afflicting small vessels of the skin, kidneys a lung ${ }^{47}$. Pulmonary hemorrhage is present in about $29 \%$ of patients (Fig. 2).

Pulmonary-renal (Goodpasteur's) syndrome is vasculitis with renal injury and alveolar hemorrhage. Positivity of the anti-GBM antibodies (antibodies against the glomerular basal membrane) is also detectable ${ }^{48}$.

Renal impairment may be present, mainly in association with polyarteritis nodosa, ANCA-associated vasculitis, Henoch-Schönlein purpura and cryoglobulinemic vasculitis.

Polyarteritis nodosa was one of the first described vasculitis. It is a rather rare disease, which affects the arteries of small and medium gauge. In many cases, it is a sequella to viral B hepatitis ${ }^{49}$. ANCA antibodies are positive in $<5 \%$ of cases. Renal injury is related to ischemic nephropathy, which may be accompanied by malignant hypertension. Renal failure may be the end-up outcome. Angiography often shows multiple vessel narrowing and microaneurysm of visceral and renal arteries. Renal insufficiency develops due to renal infarction and scaring of renal parenchyma. Aneurysm ruptures are infrequent. However, they can complicate renal biopsy outcome.
Renal ANCA positive vasculitis (granulomatis with polyangiitis, eosinophil granulomatosis with polyangiitis, microscopic polyangiitis) affect the kidneys as a pauciimmune necrotizing glomerulonephritis with sickle cell formation. It can be clinically represented by rapidly progressing glomerulonephritis (RPGN). In contrast to lupus related nephritis, pauci-immune glomerulonephritis is characterized by the absence of striking deposits of immunoglobulins or complement particles.

Henoch-Schönlein purpura presents as rather frequent vasculitis of the small vessels with multiorgan impairment (skin, gastrointestinal tract, kidney, joints). It is ANCA negative, leucocytoclastic vasculitis. Microscopic or macroscopic hematuria with mild proteinuria, sometimes even nephrotic or nephritic syndrome are manifestations of renal impairment, with variable degree of renal insufficiency. Renal symptoms may appear earlier than the skin impairments. Histomorphology of the Henoch-Schönlein purpura related nephritis shows an IgA nephropathy with variable morphology, from a focal mesangial proliferative glomerulonephritis to necrotizing forms, with sickle cell formation. The characteristic features of the disease are the mesangial deposits of IgA $\left(\right.$ ref. $\left.{ }^{50}\right)$.

Cryoglobulinemic vasculitis. Cryoglubulins are immunoglobulins, which reversibly precipitate under cool conditions (typically at $4{ }^{\circ} \mathrm{C}$ ). The type I cryoglobulin presence is typical for the monoclonal gamapathies. It is composed of monoclonal immunoglobulin with no antibody activity. Cryoglobulins types II and III are characterized by the presence of mixed cryoglobulins, composed of at least 2 types of immunoglobulins. The type II cryoglobulins are monoclonal immunoglobulins with rheumatic activity against polyclonal $\mathrm{IgG}$, the type III include polyclonal components. The type III mixed cryoglobulinemia is associated with systemic connective tissue disorders, leukemia, hepatobiliary disorders and infections. Close relationship between the mixed type II cryoglobulinemia and hepatitis $\mathrm{C}$ virus infection has been repeatedly confirmed ${ }^{51}$. Skin purpura with leucoclastic vasculitis is a manifestation of mixed cryoglobulinemia. Skin lesions may be accompanied by large ulcerations or mutilations. There are other symptoms of the disease, like fatigue, fever, arthralgia and Raynaud's syndrome, as well as peripheral neuropathy, accompanied by dysesthesia or anesthesia. Concomitant hepatosplenomegaly may often be a sign of hepatitis $\mathrm{C}$. Proteinuria and microscopic hematuria are signs of renal impairment, frequently accompanied by renal insufficiency. As clinical symptoms, there may be nephritic syndrome, hypertension or nephrotic syndrome present ${ }^{52}$. Severe renal insufficiency is more frequent in men and older patients. Laboratory exams confirm the presence of the mixed cryoglobulin, remarkable consumption of the complement components and positivity of rheumatoid factors. Renal biopsy is performed mostly in cases of type II mixed cryoglobulinemia, and shows membranoproliferative glomerulonephritis with relatively intense neutrophil and monocyte infiltrates and double contour of the basal membrane. In an acute phase 
of the nephritic syndrome we can find intraluminal amorphous eosinophilic deposits too. Avoiding hypothermia is very important, especially in case of extracorporeal circulation use, e.g. hemodialysis, continuous elimination methods or ECMO.

\section{Therapy}

The vasculitis therapy differs according to individual diagnosis and extent of organ injury. Therapy includes glucocorticoids, cyclophosphamide, azathioprine, methotrexate, cyclosporine A, immunoglobulins, together with novel medication, such as mycophenolate mofetil and rituximab are. In cases of granulomatosis with polyangiitis and/or severe, life-threatening disorder, appropriate immunosuppression plays a key role, often in combination with plasmapheresis in cases of RPGN or pulmonary hemorrhage. Timely use of glucocorticoids, cyclophosphamide and plasmapheresis may significantly improve the patient's prognosis.

Acknowledgement: Supported by Grant ČR-1528659A. Author contributions: All authors contributed equally to preparing the manuscript.

Conflict of interest statement: The authors state that there are no conflicts of interest regarding the publication of this article.

\section{REFERENCES}

1. Galve E, Candell-Riera J, Pigrau C, Permanyer-Miralda G, Garcia-DelCastillo H, Soler-Soler J. Prevalence, morphologic types, and evolution of cardiac valvular disease in systemic lupus erythematosus. $\mathrm{N}$ Engl J Med 1988;319(13):817-23.

2. Doria A, laccarino L, Sarzi-Puttini P, Atzeni F, Turriel M, Petri M. Cardiac involvement in systemic lupus erythematosus. Lupus 2005;14(9):683-6.

3. Moder KG, Miller TD, Tazelaar HD. Cardiac involvement in systemic lupus erythematosus. Mayo Clin Proc 1999;74(3):275-84.

4. Smrzova A, Horak P, Skacelova M, Zurek M, Frysakova L, Vymetal J, Vaverkova H. Cardiovascular events in patients with systemic lupus erytematodes. Cor vasa [serial on the internet].2014 Mar; [cited 2014 Oct 20]; 56:e145-e152 Available from: http://www.sciencedirect. com/science/article/pii/S0010865014000277

5. Horak $P$, Ciferska $H$, Krajsova B. Organ manifestation of rheumatic diseaseses. In: Pavelka K, Vencovský J, Horák P, Šenolt L, Mann H, Štěpán J, editors. Rheumatology. Prague: Maxdorf-Jessenius; 2012. p. 106-137.

6. Martinez-Martinez MU, Abud-Mendoza C. Diffuse alveolar hemorrhage in patients with systemic lupus erythematosus. Clinical manifestations, treatment, and prognosis. Reumatol Clin 2014;10(4):248-53.

7. Martinez-Taboada VM, Blanco R, Armona J, Fernandez-Sueiro JL, Rodriguez-Valverde V. Acute reversible hypoxemia in systemic lupus erythematosus: a new syndrome or an index of disease activity? Lupus 1995;4(4):259-62.

8. Abramson SB, Dobro J, Eberle MA, Benton M, Reibman J, Epstein $H$, Rapoport DM, Belmont HM, Goldring RM. Acute reversible hypoxemia in systemic lupus erythematosus. Ann Intern Med 1991;114(11):941-7.

9. Brey RL, Holliday SL, Saklad AR, Navarrete MG, Hermosillo-Romo D, Stallworth CL, Valdez CR, Escalante A, del Rincón I, Gronseth G, Rhine CB, Padilla P, McGlasson D. Neuropsychiatric syndromes in lupus: Prevalence using standardized definitions. Neurology 2002;58(8):1214-20.

10. Koskenmies S, Vaarala O, Widen E, Kere J, Palosuo T, Julkunen H. The association of antibodies to cardiolipin, beta 2-glycoprotein I, prothrombin, and oxidized low-density lipoprotein with thrombosis in 292 patients with familial and sporadic systemic lupus erythematosus. Scand J Rheumatol 2004;33(4):246-52.

11. Cimaz R, Meroni PL, Shoenfeld Y. Epilepsy as part of systemic lupus erythematosus and systemic antiphospholipid syndrome (Hughes syndrome). Lupus 2006;15(4):191-7.

12. Bertsias GK, loannidis JP, Aringer M, Bollen E, Bombardieri S, Bruce IN, Cervera R, Dalakas M, Doria A, Hanly JG, Huizinga TW, Isenberg D, Kallenberg C, Piette JC, Schneider M, Scolding N, Smolen J, Stara A, Tassiulas I, Tektonidou M, Tincani A, van Buchem MA, van Vollenhoven R, Ward M, Gordon C, Boumpas DT. EULAR recommendations for the management of systemic lupus erythematosus with neuropsychiatric manifestations: report of a task force of the EULAR standing committee for clinical affairs. Ann Rheum Dis 2010;69(12):2074-82.

13. Bertsias GK, Tektonidou M, Amoura Z, Aringer M, Bajema I, Berden JH, Boletis J, Cervera R, Dörner T, Doria A, Ferrario F, Floege J, Houssiau FA, loannidis JP, Isenberg DA, Kallenberg CG, Lightstone L, Marks SD, Martini A, Moroni G, Neumann I, Praga M, Schneider M, Starra A, Tesar V, Vasconcelos C, van Vollenhoven RF, Zakharova H, Haubitz M, Gordon C, Jayne D, Boumpas DT. Joint European League Against Rheumatism and European Renal Association-European Dialysis and Transplant Association (EULAR/ERA-EDTA) recommendations for the management of adult and paediatric lupus nephritis. Ann Rheum Dis 2012;71(11):1771-82.

14. Weening JJ, D'Agati VD, Schwartz MM, Seshan SV, Alpers CE, Appel GB, Balow JE, Bruijn JA, Cook T, Ferrario F, Fogo AB, Ginzler EM, Hebert L, Hill G, Hill P, Jennette JC, Kong NC, Lesavre P, Lockshin M, Looi LM, Makino H, Moura LA, Nagata M. Nagata M. The classification of glomerulonephritis in systemic lupus erythematosus revisited. J Am Soc Nephrol 2004;15(2):241-50.

15. Hughson MD, Nadasdy T, McCarty GA, Sholer C, Min KW, Silva F. Renal thrombotic microangiopathy in patients with systemic lupus erythematosus and the antiphospholipid syndrome. Am J Kidney Dis 1992;20(2):150-8.

16. Dhingra S, Qureshi R, Abdellatif A, Gaber LW, Truong LD. Tubulointerstitial nephritis in systemic lupus erythematosus: innocent bystander or ominous presage. Histol Histopathol 2014;29(5):553-65.

17. Petri M, Howard D, Repke J. Frequency of lupus flare in pregnancy. The Hopkins Lupus Pregnancy Center experience. Arthritis Rheum 1991;34(12):1538-45.

18. Stojan G, Baer AN. Flares of systemic lupus erythematosus during pregnancy and the puerperium: prevention, diagnosis and management. Expert Rev Clin Immunol 2012;8(5):439-53.

19. Horak P, Tegzova D, Závada Z, Olejárová M, Skácelová M, Smržová A, Žurek M. Recommendantion Czech Society of Rheumatology for treatment of patients with SLE. Ces Revmatol 2013;21:110-22.

20. Xiong W, Lahita RG. Pragmatic approaches to therapy for systemic lupus erythematosus. Nat Rev Rheumatol. 2014;10(2):97-107.

21. Dall'era M, Chakravarty EF. Treatment of mild, moderate, and severe lupus erythematosus: focus on new therapies. Curr Rheumatol Rep. 2011;13(4):308-16.

22. Ruiz-Arruza I, Ugarte A, Cabezas-Rodriguez I, Medina JA, Moran MA, Ruiz-Irastorza G. Glucocorticoids and irreversible damage in patients with systemic lupus erythematosus. Rheumatology (Oxford) 2014;53(8):1470-6.

23. Miyakis S, Lockshin MD, Atsumi T, Branch DW, Brey RL, Cervera R, Derksen RH, DE Groot PG, Koike T, Meroni PL, Reber G, Shoenfeld Y, Tincani A, Vlachoyiannopoulos PG, Krilis SA. International consensus statement on an update of the classification criteria for definite antiphospholipid syndrome (APS). J Thromb Haemost 2006;4(2):295306.

24. Ruffatti A, Salvan E, Del Ross T, Gerosa M, Andreoli L, Maina A, Alijotas-Reig J, De Carolis S, Mekinian A, Bertero MT, Canti V, Brucato A, Bremme K, Ramoni V, Mosca M, Di Poi E, Caramaschi P, Galeazzi M, Tincani A, Trespidi L. Treatment strategies and pregnancy outcomes in antiphospholipid syndrome patients with thrombosis and triple antiphospholipid positivity. A European multicentre retrospective study Thromb Haemost. 2014;112(4):727-35.

25. Nayer A, Ortega LM. Catastrophic antiphospholipid syndrome: a clinical review. J Nephropathol 2014;3(1):9-17.

26. Keeling D, Mackie I, Moore GW, British Committee for Standards in Haematology. Guidelines on the investigation and management of antiphospholipid syndrome, Br J Haematol 2012;157(1):47-58. 
27. Becvar R, Soukup T, Stork J, Suchy D, Nemec P, Jansa P, Fojtik Z, Horak $P$, Nemcova D. Recommendation Czech Society of Rheumatology for diagnostics systemic scleroderma. Ces Revmatol 2014;22(2):51-68.

28. Steen VD, Syzd A, Johnson JP, Greenberg A, Medsger TA Jr. Kidney disease other than renal crisis in patients with diffuse scleroderma. J Rheumatol 2005;32(4):649-55.

29. Denton CP, Lapadula G, Mouthon L, Müller-Ladner U. Renal complications and scleroderma renal crisis. Rheumatology (Oxford) 2009;48(Suppl 3):S32-5.

30. Batal I, Domsic RT, Medsger TA, Bastacky S. Scleroderma renal crisis: a pathology perspective. Int J Rheumatol [serial on the internet]. 2010 Jul [cited 2014 Oct 20]. Available from: http://www.ncbi.nlm. nih.gov/pmc/articles/PMC2958499/

31. Mouthon L, Bussone G, Berezné A, Noël LH, Guillevin L. Scleroderma renal crisis. J Rheumatol. 2014;41(6):1040-8.

32. Steen VD. Kidney involvement in systemic sclerosis. Presse Med [serial on the internet]. 2014 Oct [cited 2014 Aug 28]; 43(10 Pt 2):e30514. Available from: http://www.sciencedirect.com/science/article/ pii/S0755498214003327

33. Steen VD, Conte C, Owens GR, Medsger TA Jr. Severe restrictive lung disease in systemic sclerosis. Arthritis Rheum 1994;37(9):1283-9.

34. Luo Y, Xiao R. Interstitial Lung Disease in Scleroderma: Clinica Features and Pathogenesis. Rheumatology 2011 doi:10.4172/21611149. S1-002. Available from: http://omicsonline.org/ interstitial-lung-disease-in-scleroderma-clinical-features-andpathogenesis-2161-1149.S1-002.pdf

35. Wells AU. Interstitial lung disease in systemic sclerosis. Presse Med. 2014 Oct;43(10 Pt 2):e329-43.

36. Coghlan JG, Denton CP, Grünig E, Bonderman D, Distler O, Khanna D, Müller-Ladner U, Pope JE, Vonk MC, Doelberg M, Chadha-Boreham $\mathrm{H}$, Heinzl H, Rosenberg DM, McLaughlin VV, Seibold JR. Evidencebased detection of pulmonary arterial hypertension in systemic sclerosis: the DETECT study. Ann Rheum Dis 2014;73(7):1340-9.

37. Jansa $P$, Becvar $R$, Ambroz $D$, Palecek $T$, Tomcik $M$, Skacelova $S$ Aschermann M, Linhart A. Pulmonary arterial hypertension associated with systemic sclerosis in the Czech Republic. Clin Rheumatol 2012;31(3):557-61.

38. Aschermann $M$, Jansa P. Drug therapy of pulmonary arterial hypertension in 2014. Vnitr Lek 2014;60(4):282-8.

39. Hallowell RW, Ascherman DP, Danoff SK. Pulmonary manifestations of polymyositis/dermatomyositis. Semin Respir Crit Care Med 2014;35(2):239-48

40. Maldonado F, Patel RR, lyer VN, Ryu JH. Are respiratory complications common causes of death in inflammatory myopathies? An autopsy study. Respirology 2012;17(3):455-60.
41. Fujisawa $T$, Hozumi $H$, Kono $M$, Enomoto $N$, Hashimoto $D$, Nakamura Y, Inui N, Yokomura K, Koshimizu N, Toyoshima M, Shirai T, Yasuda K, Hayakawa H, Suda T. Prognostic factors for myositis-associated interstitial lung disease. PLoS One [serial on the internet] 2014 Jun [cited 2014 Oct 20]; Available from: http://www.ncbi.nlm.nih.gov/ pmc/articles/PMC4048238/?report=classic

42. Hruskova Z, Casian AL, Konopasek P, Svobodova B, Frausova D, Lanska V, Tesar V, Jayne DR. Long-term outcome of severe alveolar haemorrhage in ANCA-associated vasculitis: a retrospective cohort study. Scand J Rheumatol. 2013;42(3):211-4.

43. Niles JL, Böttinger EP, Saurina GR, Kelly KJ, Pan G, Collins AB, McCluskey RT. The syndrome of lung hemorrhage and nephritis is usually an ANCA-associated condition. Arch Intern Med 1996;156(4):440-5.

44. Capizzi SA, Specks U. Does infection play a role in the pathogenesis of pulmonary vasculitis? Semin Respir Infect 2003;18(1):17-22.

45. Guillevin L, Cohen P, Gayraud M, Lhote F, Jarrousse B, Casassus P. Churg-Strauss syndrome. Clinical study and long-term follow-up of 96 patients. Medicine (Baltimore) 1999;78(1):26-37.

46. Vaglio A, Buzio C, Zwerina J. Eosinophilic granulomatosis with polyangiitis (Churg-Strauss): state of the art. Allergy 2013;68(3):261-73.

47. Guillevin L, Durand-Gasselin B, Cevallos R, Gayraud M, Lhote F, Callard P, Amouroux J, Casassus P, Jarrousse B. Microscopic polyangiitis: clinical and laboratory findings in eighty-five patients. Arthritis Rheum 1999;42(3):421-30.

48. Hellmark T, Segelmark M. Diagnosis and classification of Goodpasture's disease (anti-GBM). J Autoimmun [serial on the internet]. 2014 Jan 21 [cited 2014 Oct 20]. (48) p. 108-112. Available from: http://www.sciencedirect.com/science/article/pii/ S0896841114000274

49. Guillevin L, Mahr A, Callard P, Godmer P, Pagnoux C, Leray E, Cohen, French Vasculitis Study Group. Hepatitis B virus-associated polyarteritis nodosa: clinical characteristics, outcome, and impact of treatment in 115 patients. Medicine (Baltimore) 2005;84(5):313-22.

50. Pillebout E, Thervet E, Hill G, Alberti C, Vanhille P, Nochy D. HenochSchönlein Purpura in adults: outcome and prognostic factors. J Am Soc Nephrol 2002;13(5):1271-8.

51. Misiani R, Bellavita P, Fenili D, Borelli G, Marchesi D, Massazza M Vendramin G, Comotti B, Tanzi E, Scudeller G. Hepatitis C virus infection in patients with essential mixed cryoglobulinemia. Ann Intern Med 1992;117(7):573-7.

52. Zaidan M, Mariotte E, Galicier L, Arnulf B, Meignin V, Vérine J, Mahr A, Azoulay E. Vasculitic emergencies in the intensive care unit: a special focus on cryoglobulinemic vasculitis. Annals of Intensive Care [serial on the internet]. 2012 Jul [cited 2014 Oct 20]; Available from: http:// www.ncbi.nlm.nih.gov/pmc/articles/PMC3488028/ 